\title{
Kohlschütter-Tönz Syndrome - Report of an additional case
}

\author{
Wilfredo Alejandro González-Arriagada ${ }^{1,2}$, Román Carlos-Bregni $^{3}$, Elisa Contreras ${ }^{3}$, Oslei Paes de Almeida ${ }^{4}$, \\ Marcio Ajudarte Lopes ${ }^{4}$
}

${ }^{1}$ DDS, MSc. Oral Diagnosis Department, Semiology and Oral Pathology, Piracicaba Dental School, State University of Campinas (UNICAMP), Piracicaba, Sao Paulo, Brazil.

${ }^{2}$ Assistant professor. Oral Pathology and Diagnosis, Facultad de Odontología, Universidad de Valparaíso, Valparaíso, Chile.

${ }^{3}$ DDS. Oral Pathology Section, Centro Clínico de Cabeza y Cuello/Hospital Herrera Llerandi, Guatemala City, Guatemala.

${ }^{4}$ DDS, PhD. Oral Diagnosis Department, Semiology and Oral Pathology, Piracicaba Dental School, State University of Campinas (UNICAMP), Piracicaba, Sao Paulo, Brazil.

Correspondence:

Área de Semiologia,

Faculdade de Odontologia de Piracicaba-UNICAMP

Av. Limeira, 901, Bairro Areião, Piracicaba,

São Paulo Brazil, CEP: 13.414-903.

E-mail:malopes@fop.unicamp.br

González-Arriagada WA, Carlos-Bregni R, Contreras E, Almeida OP, Lopes MA. Kohlschütter-Tönz Syndrome - Report of an additional case. J Clin Exp Dent. 2013;5(2):e108-11. http://www.medicinaoral.com/odo/volumenes/v5i2/jcedv5i2p108.pdf

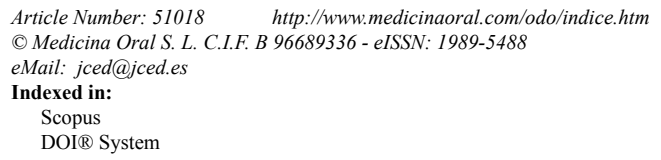

\begin{abstract}
Kohlschütter-Tönz Syndrome is a rare disorder clinically characterized by amelogenesis imperfecta, epilepsy and progressive mental deterioration. We present an additional case of this syndrome of a nine year-old boy who was referred by pigmented teeth. The mental deterioration was associated with speech delay, impulsive behavior, attention-deficit/hyperactivity disorder, and learning problems. The physical examination revealed a reduction of lower third, slightly palpebral fissures, low ear and hair implantation, coarse hair and hypertrichosis. The intraoral examination showed alteration in teeth pigmentation diagnosed as amelogenesis imperfecta. Although rare, the present case report illustrates a syndrome that has dental anomalies and systemic alterations. It is important to recognize this syndrome as early as possible and paediatric dentist may contribute to the diagnosis and consequently to better manage the patients.
\end{abstract}

Key words: Kohlschütter-Tönz syndrome, amelogenesis imperfecta, seizures, mental deterioration. 


\section{Introduction}

Kohlschütter-Tonz Syndrome is an uncommon disorder that has been associated with an autosomal recessive inheritance. Clinically it is characterized by amelogenesis imperfecta, epilepsy and progressive mental deterioration. Other clinical manifestations such as myopia, ventricular enlargement, dry skin and altered thumbs/toes also have been described (1-5).

This disorder was described by Kohlschütter et al. (1) in 1974 and forty-three cases have been reported in the English-language literature (1-11). In the present paper we describe an additional case with the typical features of this syndrome and a brief literature review.

\section{Case Report}

A nine-year-old boy was referred for evaluation because of pigmentation of his teeth. Her mother stated that her pregnancy was of high risk, and that she took fenobarbital during this period. The boy was born with a normal birth weight of $4.500 \mathrm{~g}(10 \mathrm{lbs})$. His past medical history revealed that he underwent amygdalectomy when he was 4 years-old. When he was 8 years-old he presented generalized tonic-clonic seizure, and was treated with valproic acid. A brain angiotomography was performed and any alterations were found. However, the boy manifested mental deterioration and hyperactivity. The patient is in neurological follow-up because speech delay, impulsive behavior, attention-deficit/hyperactivity disorder, and learning problems. He was treated with atomoxetine hydrochloride in association with risperidone, presenting improvement in learning and behavior. The mother also reported that he has excessive sweating.



Fig. 1. Extraoral examination showing low ear and hair implantation, and a slight reduction in the lower third of the face.
In the extraoral examination (Fig. 1) the patient showed a symmetric face but with a reduction of lower third, slightly palpebral fissures, low ear and hair implantation, coarse hair and hypertrichosis. The intraoral examination showed crowding teeth with generalized enamel defects in all the teeth, suggesting the clinical diagnosis of amelogenesis imperfecta with a yellow-brownish coloration, and high incidence of caries (Fig. 2). The orthopantomography showed no alterations and normal teeth eruption. Blood and urine test had normal values. Electrolyte analysis of chloride presented a slight elevated value $(107.2 \mathrm{mEq} / \mathrm{L}$; ref. $95-106 \mathrm{mEq} / \mathrm{L})$. The ophtalmological evaluation did not reveal any alteration.

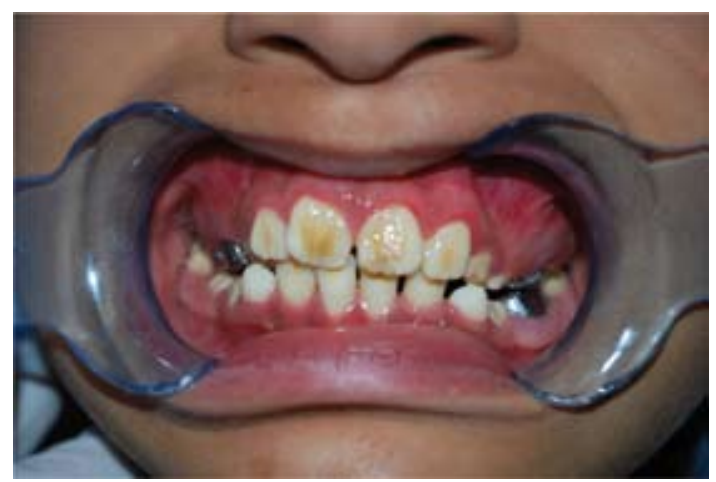

Fig. 2. Intraoral examination showing metal molar crowns and tooth discoloration.

\section{Discussion}

Previously, forty-three cases of Kohlschütter-Tönz Syndrome have been reported in the English-language literature (Table 1). The typical characteristics of this syndrome (amelogenesis imperfecta, early onset seizures and progressive mental retardation) have been observed in all the reported cases, but with a variable expressivity (1-5, 7-11). The dental abnormalities affect both primary and secondary dentition (10). The enamel malformation is associated with a high susceptibility to caries (9), and this can be observed in intraoral pictures of the current patient. Delayed eruption have been reported in some patients (9). This disorder is always diagnosed in young child (0-4 years-old) when they present the first convulsion (1). These seizures are usually treatment resistant to various anti-epileptic agents, and the patient present psychomotor delay or regression in infancy, associated to spasticity of the lower and upper limbs. Severe progressive psychomotor decline and fatal outcome has been reported in some patients (9). The inherited cause of this disorder is supported by the reported familial cases and consanguinity, suggesting autossomal recessive inheritance, confirmed by recent reported findings (1, $3-5,9)$. In our case the parents have not consanguinity and the patient does not have brothers. The cause of the progressive mental deterioration is unknown, but have been associated with the seizures, that could cause a 
Table 1. Previously reported cases of Kohlschütter-Tönz Syndrome, including clinical features.

\begin{tabular}{|c|c|c|c|c|c|c|c|}
\hline Author/year & Gen & OE & DD & Seiz & Spa & AI & Others \\
\hline Kohlschütter/1974 (1) & $\mathrm{M}$ & $19 \mathrm{mo}$ & Yes & Yes & Yes & Yes & Death at age $7 \mathrm{y}$. \\
\hline Kohlschütter/1974 (1) & M & $21 \mathrm{mo}$ & Yes & Yes & Yes & Yes & Death at age $4 \mathrm{y}$. \\
\hline Kohlschütter/1974 (1) & M & $4 y$ & Yes & Yes & Yes & Yes & Death at age $9 \mathrm{y}$. \\
\hline Kohlschütter/1974 (1) & M & $18 \mathrm{mo}$ & Yes & Yes & Yes & Yes & Death at age $4 \mathrm{y}$. \\
\hline Kohlschütter/1974 (1) & M & $11 \mathrm{mo}$ & Yes & Yes & Yes & Yes & Secondary microcephaly and enlarged ventricles \\
\hline Haberlandt/2006 (2) & M & $8 \mathrm{mo}$ & Yes & Yes & No & Yes & Cerebellar hypoplasia \\
\hline Christodoulou/1988 (3) & M & $11 \mathrm{mo}$ & Yes & Yes & No & Yes & No speech, death at age $10 \mathrm{y}$. \\
\hline Christodoulou/1988 (3) & M & $18 \mathrm{mo}$ & Yes & Yes & No & Yes & Alive at age $12 \mathrm{y}$. \\
\hline Christodoulou/1988 (3) & M & $13 \mathrm{mo}$ & Yes & Yes & No & Yes & Death at age $10 \mathrm{y}$. \\
\hline Christodoulou/1988 (3) & $\mathrm{F}$ & $11 \mathrm{mo}$ & Yes & Yes & No & Yes & Death at age $1.5 \mathrm{y}$. \\
\hline Christodoulou/1988 (3) & $\mathrm{F}$ & $22 \mathrm{mo}$ & Yes & Yes & No & Yes & Alive at age $6 \mathrm{y}$. \\
\hline Christodoulou/1988 (3) & M & $7 \mathrm{mo}$ & Yes & Yes & No & Yes & Alive at age $1.5 \mathrm{y}$. \\
\hline Musumeci/1995 (4) & M & $2 \mathrm{mo}$ & Yes & Yes & Yes & Yes & $\begin{array}{l}\text { Vermis hypoplasia and asymmetric dilation of the ventri- } \\
\text { cle, no language, secondary microcephaly }\end{array}$ \\
\hline Musumeci/1995 (4) & $\mathrm{F}$ & $10 \mathrm{mo}$ & Yes & Yes & Yes & Yes & $\begin{array}{c}\text { Enlargement of the lateral ventricles, secondary micro- } \\
\text { cephaly }\end{array}$ \\
\hline Zlotogora/1993 (5) & M & $3 y$ & Yes & Yes & Yes & Yes & \\
\hline Zlotogora/1993 (5) & $\mathrm{F}$ & $12 \mathrm{mo}$ & Yes & Yes & No & Yes & Congenital nystagmus \\
\hline Donnai/2005 (6) & M & $1 \mathrm{mo}$ & Yes & Yes & No & Yes & $\begin{array}{c}\text { No language, no purposeful hand use, brain atrophy, } \\
\text { cerebellar hypoplasia }\end{array}$ \\
\hline Donnai/2005 (6) & $\mathrm{F}$ & $1 \mathrm{mo}$ & Yes & Yes & No & Yes & $\begin{array}{c}\text { Enlarged ventricles, no language, gastrostomy feeding, } \\
\text { scoliosis }\end{array}$ \\
\hline Mory/2012 (7) & $\mathrm{F}$ & $13 \mathrm{mo}$ & Yes & Yes & $\mathrm{X}$ & Yes & Alive at age $6 \mathrm{y} .$, abnormal brain MRI \\
\hline Mory/2012 (7) & $\mathrm{F}$ & $12 \mathrm{mo}$ & Yes & Yes & $\mathrm{X}$ & Yes & Alive at age $24 \mathrm{y}$, , abnormal brain MRI \\
\hline Mory/2012 (7) & M & $9 \mathrm{mo}$ & Yes & Yes & $\mathrm{X}$ & Yes & Alive at age $16 \mathrm{y}$, abnormal brain MRI \\
\hline Mory/2012 (7) & $\mathrm{F}$ & $12 \mathrm{mo}$ & Yes & Yes & $\mathrm{X}$ & Yes & Alive at age $15 \mathrm{y}$. \\
\hline Mory/2012 (7) & M & $6 \mathrm{mo}$ & Yes & Yes & $\mathrm{X}$ & Yes & Alive at age $16 \mathrm{y} .$, abnormal EEG \\
\hline Mory/2012 (7) & M & $3 y$ & Yes & Yes & $\mathrm{X}$ & Yes & Alive at age $13 \mathrm{y}$. \\
\hline Mory/2012 (7) & M & $9 \mathrm{mo}$ & Yes & Yes & $\mathrm{X}$ & Yes & Alive at age $9 \mathrm{y}$. \\
\hline Mory/2012 (7) & $\mathrm{F}$ & $9 \mathrm{mo}$ & Yes & Yes & $\mathrm{X}$ & Yes & Alive at age $9 \mathrm{y}$. \\
\hline Mory/2012 (7) & $\mathrm{F}$ & birth & $\mathrm{X}$ & Yes & $\mathrm{X}$ & $\mathrm{X}$ & Death at age $2 \mathrm{y}$. \\
\hline Mory/2012 (7) & M & $10 \mathrm{mo}$ & Yes & Yes & $\mathrm{X}$ & Yes & Alive at age $10 \mathrm{y}$, abnormal brain MRI, abnormal EEG \\
\hline Mory/2012 (7) & $\mathrm{F}$ & $9 \mathrm{mo}$ & Yes & Yes & $\mathrm{X}$ & Yes & Alive at age $9 \mathrm{y}$. \\
\hline Mory/2012 (7) & $\mathrm{F}$ & $9 \mathrm{mo}$ & Yes & Yes & $\mathrm{X}$ & Yes & Alive at age $9 \mathrm{y}$. \\
\hline Mory/2012 (7) & M & $9 \mathrm{mo}$ & Yes & Yes & $\mathrm{X}$ & Yes & Alive at age $9 \mathrm{y}$. \\
\hline Mory/2012 (7) & M & $11 \mathrm{mo}$ & Yes & Yes & $\mathrm{X}$ & Yes & Alive at age 9 y., abnormal EEG \\
\hline Petermöller/1993 (8) & M & $8 \mathrm{mo}$ & Yes & Yes & No & Yes & Ventricular enlargement, alive at age $5 \mathrm{y}$. \\
\hline Petermöller/1993 (8) & $\mathrm{F}$ & $8 \mathrm{mo}$ & Yes & Yes & No & Yes & Speech problems, alive at age $3 \mathrm{y}$. \\
\hline Schossig/2012 (9) & M & $4 \mathrm{mo}$ & Yes & Yes & No & Yes & Delayed myelination, no language, alive at age $12 \mathrm{y}$. \\
\hline Schossig/2012 (9) & $\mathrm{F}$ & $12 \mathrm{mo}$ & Yes & Yes & No & Yes & $\begin{array}{l}\text { Alive at age } 9 \text { y., slight atrophy } \\
\text { of cerebellar vermis }\end{array}$ \\
\hline Schossig/2012 (9) & M & $11 \mathrm{mo}$ & Yes & Yes & No & Yes & $\begin{array}{l}\text { No language, atrophy } \\
\text { of cerebellar vermis }\end{array}$ \\
\hline Schossig/2012 (9) & $\mathrm{F}$ & $6 \mathrm{mo}$ & Yes & Yes & No & Yes & Alive at age $11 \mathrm{y}$. \\
\hline Tucci/2012 (10) & M & $7 \mathrm{mo}$ & Yes & Yes & No & Yes & Cognitive problems and microcephaly \\
\hline Tucci/2012 (10) & M & $8 \mathrm{mo}$ & Yes & Yes & Yes & Yes & $\begin{array}{l}\text { Hip dislocations and scoliosis, speech and learning } \\
\text { problems }\end{array}$ \\
\hline Tucci/2012 (10) & M & $\mathrm{X}$ & Yes & Yes & No & Yes & $\begin{array}{c}\text { Cognitive problems, atrophy of vermis and small pons, } \\
\text { hipermobility of joints }\end{array}$ \\
\hline Tucci/2012 (10) & $\mathrm{F}$ & $18 \mathrm{mo}$ & No & Yes & No & Yes & No neurological abnormalities besides mild clumsiness \\
\hline Wygold/1996 (11) & M & $6 \mathrm{mo}$ & Yes & No & No & Yes & $\begin{array}{c}\text { Cerebral atrophy, bilateral atrophy } \\
\text { of basal ganglia, secondary microcephaly }\end{array}$ \\
\hline Current case $/ 2012$ & M & $8 \mathrm{y}$ & Yes & Yes & Yes & Yes & Speech delay and learning problems \\
\hline
\end{tabular}

$O E=$ onset of epilepsy; $m o=$ moths; $y=$ years; Gen = gender $; D D=$ developmental delay; Seiz = seizures; Spa = spasticity; AI = amelogenesis imperfecta; $M=$ male; $F=$ female; $X=$ without information; $M R I=$ magnetic resonance imaging; $E E G=$ electroencephalogram. 
brain damage difficult to be controlled (2). Musumeci et al. (4), suggested that this syndrome is a neurodegenerative disease caused by a metabolic disturbance, but any metabolic alteration was reported. Laboratoy blood and cerebrospinal fluid, and histopathological reported findings are unremarkable or inconclusive $(1,6,9)$. Our patient presents the characteristics of the KohlschütterTönz syndrome in a low grade, being the mental deterioration the most severe problem. The mother of the patient affirmed that there were not relatives affected by amelogenesis imperfecta or another sign of the disease, being considered as an isolated case without familiar inheritance.

Associated anomalies are described but they are not constant (9). Reported patients have minor physical abnormalities such as small stature, microcephaly, scoliosis, broad thumbs and toes, café-aut-lait spots and vitiligo, bristly hair, deeply set eyes, palpebral fissures, small ears, short nose, concave nasal ridge and smooth philtrum (1, 4, 6, 9-11). Magnetic resonance imaging (MRI) and computed tomography (CT) findings were reported in previous cases, showing additional abnormalities in brain (9). These image scans were not performed in our patient. Recently, mutations on RODGI in chromosome 16 (MIM\# 614574), a gene that encodes a protein of unknown function, and genetic heterogeneity was reported $(10,12)$. The gene has orthologs in many species, including Drosophila melanogaster and it shows high expression levels in various human brain regions (7, 12). A Drosophila mutant of this gene showed a possible deficiency in olfactory memory (7). The differential diagnosis can include Rud syndrome, tuberous sclerosis, mucopolysaccharidosis, oculodentodigital dysplasia and isolated or syndromic amelogenesis imperfecta, but it is very limited and these disorders can be easily distinguished because mainly the progression $(2,4)$. The treatment of these patients is based in the following by the neurologist for the epilepsy and the mental retardation and the dentist because the high risk of caries in the patients with amelogenesis imperfecta. Because the rarity of this disorder the report of new cases is necessary for a better clinical and genetic characterization.

\section{References}

1. Kohlschütter A, Chappuis D, Meier C, Tönz O, Vassella F, Herschkowitz N. Familial epilepsy and yellow teeth--a disease of the CNS associated with enamel hypoplasia. Helv Paediatr Acta. 1974;29:283-94.

2. Haberlandt E, Svejda C, Felber S, Baumgartner S, Gunther B, Utermann $\mathrm{G}$ et al. Yellow teeth, seizures, and mental retardation: a less severe case of Kohlschütter-Tönz syndrome. Am J Med Genet A. 2006;140:281-3.

3. Christodoulou J, Hall RK, Menahem S, Hopkins IJ, Rogers JG. A syndrome of epilepsy, dementia, and amelogenesis imperfecta: genetic and clinical features. J Med Genet. 1988;25:827-30.

4. Musumeci SA, Elia M, Ferri R, Romano C, Scuderi C, Del Gracco S. A further family with epilepsy, dementia and yellow teeth: the Kohlschütter syndrome. Brain Dev. 1995;17:133-8.
5. Zlotogora J, Fuks A, Borochowitz Z, Tal Y. Kohlschütter-Tönz syndrome: epilepsy, dementia, and amelogenesis imperfecta. Am J Med Genet. 1993;46:453-4.

6. Donnai D, Tomlin PI, Winter RM. Kohlschütter syndrome in siblings. Clin Dysmorphol. 2005;14:123-6.

7. Mory A, Dagan E, Illi B, Duquesnoy P, Mordechai S, Shahor I et al. A nonsense mutation in the human homolog of Drosophila rogdi causes Kohlschütter-Tönz syndrome. Am J Hum Genet. 2012;90:708-14.

8. Petermoller M, Kunze J, Gross-Selbeck G. Kohlschütter syndrome: syndrome of epilepsy--dementia--amelogenesis imperfecta. Neuropediatrics. 1993;24:337-8.

9. Schossig A, Wolf NI, Kapferer I, Kohlschütter A, Zschocke J. Epileptic encephalopathy and amelogenesis imperfecta: KohlschütterTönz syndrome. Eur J Med Genet. 2012;55:319-22.

10. Tucci A, Kara E, Schossig A, Wolf NI, Plagnol V, Fawcett K et al. Kohlschütter-Tönz Syndrome: Mutations in ROGDI and Evidence of Genetic Heterogeneity. Hum Mutat. 2012.

11. Wygold T, Kurlemann G, Schuierer G. Kohlschütter syndrome--an example of a rare progressive neuroectodermal disease. Case report and review of the literature. Klin Padiatr. 1996;208:271-5.

12. Schossig A, Wolf NI, Fischer C, Fischer M, Stocker G, Pabinger S et al. Mutations in ROGDI Cause Kohlschütter-Tönz Syndrome. Am J Hum Genet. 2012;90:701-7. Epub 2012 Mar 15. 